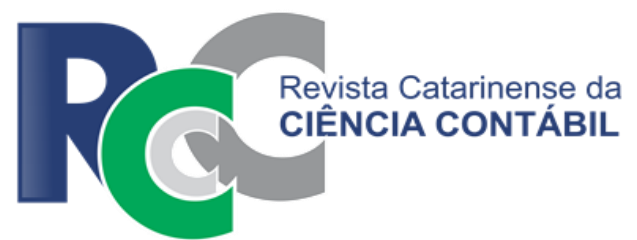

\title{
APLICAC̄ÃO DA ANÁLISE FATORIAL PARA IDENTIFICAÇÃO DOS PRINCIPAIS INDICADORES DE DESEMPENHO ECONÔMICO-FINANCEIRO EM INSTITUIÇÕES FINANCEIRAS BANCÁRIAS*
}

\author{
APPLICATION OF FACTOR ANAL YSIS TO IDENTIFY THE MAIN INDICATORS OF \\ ECONOMIC AND FINANCIAL PERFORMANCE IN BANKING FINANCIAL \\ INSTITUTIONS
}

\begin{abstract}
JÚLIA ALVES E SOUZA
Doutoranda em Administração (com ênfase em Controladoria e Finanças) pela Universidade Federal de Lavras (UFLA). Mestre em Ciências Contábeis pela Universidade Federal do Espírito Santo (UFES). Endereço: Departamento de Administração e Economia, Bloco III, Campus Universitário UFLA / 37200-000 / Lavras/MG / Brasil. E-mail: julia.jasouza@gmail.com
\end{abstract}

\section{DOUGLAS JOSÉ MENDONÇA}

Mestrando em Administração (com ênfase em Controladoria e Finanças) pela Universidade Federal de Lavras (UFLA). Endereço: Departamento de Administração e Economia, Bloco III, Campus Universitário UFLA / 37200-000 / Lavras/MG / Brasil.

E-mail: mendonca_douglas@yahoo.com.br

\section{GIDEON CARVALHO DE BENEDICTO \\ Doutor em Controladoria e Contabilidade pela Universidade de São Paulo (USP). Professor Adjunto da Universidade Federal de Lavras (UFLA). Endereço: Caixa Postal, 122 | 37200-000 | Lavras/MG / Brasil. \\ E-mail: gideon.benedicto@gmail.com}

\section{FRANCISVAL DE MELO CARVALHO}

Doutor em Administração de Empresas da Universidade Presbiteriana Mackenzie (UPM). Professor Associado da Universidade Federal de Lavras (UFLA). Endereço: Departamento de Administração e Economia, Bloco III, Campus Universitário UFLA / 37200-000 | Lavras/MG / Brasil.

E-mail: francarv@dae.ufla.br

\section{RESUMO}

Este estudo tem como objetivo identificar, por meio da análise fatorial, os indicadores econômico-financeiros mais relevantes para a avaliação do desempenho das instituições financeiras bancárias. São englobadas 118 instituições financeiras bancárias com atividades no Brasil, ao longo dos anos de 2011 a 2014. Realiza-se um estudo quantitativo e descritivo. Para a análise dos dados, utiliza-se a técnica estatística de análise fatorial. No processo de aplicação da técnica, verificou-se a adequação geral do modelo e de cada uma das variáveis, de forma a identificar os principais indicadores que deverão compor as avaliações de instituições bancárias. O estudo foi desenvolvido a partir de um conjunto inicial de 17 indicadores, utilizados para analisar o desempenho econômico-financeiro de tais instituições. 
Seguindo os critérios das técnicas de análise fatorial, foram selecionados os indicadores que explicam o máximo de variância a partir do menor número possível de variáveis. Os resultados mostram que os indicadores mais relevantes para a avaliação do desempenho dessas instituições são: Retorno sobre o Investimento Total, Margem Líquida, Retorno sobre o Patrimônio Líquido, Relação Capital/Depositantes, Índice Empréstimos/Depósitos, Liquidez Imediata, Encaixe Voluntário e Índice de Sensibilidade de Juros. Esses 8 indicadores podem, ainda, ser substituídos por 3 fatores, os quais explicam aproximadamente $89,23 \%$ da variância total dos dados. Os fatores "Rentabilidade e Lucratividade", "Capital e Liquidez" e "Encaixe e Sensibilidade aos Juros" permitem classificar e comparar o desempenho das instituições financeiras bancárias.

Palavras-chave: Indicadores econômico-financeiros. Análise das demonstrações contábeis. Contabilidade bancária. Análise fatorial.

\begin{abstract}
This study aims at identifying the most relevant economic and financial indicators for evaluating the performance of banking financial institutions by using the factor analysis. A total of 118 banking financial institutions with activities in Brazil over the years 2011 to 2014 are encompassed. It was carried out a quantitative and descriptive study. For data analysis, the statistical technique of factor analysis was used. In the application process of that technique, the overall appropriateness of the model and of each variable were verified, in order to identify key indicators that will compose the analysis of banks. The study was developed from an initial set of 17 indicators used to analyze the economic and financial performance of such institutions. Following the criteria of factor analysis techniques, the indicators that explain the maximum of variance from the smallest possible number of variables were selected. The results show that the most relevant indicators for evaluating the performance of such institutions are: Return on Total Investment, Net Margin, Return on Equity, Ratio of Capital to Deposits, Loans/Deposits Ratio, Immediate Liquidity, Voluntary Fit and Interest Rate Sensitivity. These 8 indicators can also be replaced by 3 factors, which explain about $89,23 \%$ of the overall data range. The factors "Profitability and Profitability", "Capital and Liquidity" and "Fitting and Interest Sensitivity" allow us to classify and compare the performance of banking financial institutions.
\end{abstract}

Keywords: Economic and financial indicators. Analysis of the financial statements. Bank Accounting. Factor analysis.

\title{
1 INTRODUÇÃO
}

As instituições financeiras bancárias desempenham um papel importante para a economia de um país e consistem no principal canal de intermediação financeira (Zha, Liang \& Bian, 2016). Devido às características específicas dessa intermediação, o gerenciamento econômico-financeiro de tais instituições apresenta algumas particularidades. $O$ desenvolvimento de modelos que contribuam para análise de desempenho e permitam a comparação entre diferentes instituições financeiras é importante para o processo de tomada de decisões tanto para os agentes internos quanto para aqueles externos a essas instituições.

Uma metodologia muito utilizada para que se faça a análise do desempenho econômico-financeiro das organizações é a criação de indicadores por meio da análise das demonstrações contábeis. O principal objetivo da análise das demonstrações contábeis é extrair informações que favoreçam a tomada de decisões. A utilização dos indicadores permite que o analista extraia tendências e compare os índices com padrões preestabelecidos (Matarazzo, 2010). Conforme Brigham e Ehrhardt (2016), por meio da análise de indicadores é possível realizar uma comparação padronizada das empresas, uma vez que os indicadores financeiros são desenvolvidos para extrair informações que podem não ser óbvias ao se examinar as demonstrações financeiras. 
A avaliação de desempenho das empresas do setor bancário também pode ser realizada por meio da análise das demonstrações contábeis. Alguns autores propõem indicadores específicos para as instituições financeiras, os quais consideram as especificidades desse tipo de organização. Nesse contexto, Assaf (2012) apresenta um conjunto de 17 indicadores adaptados a esse tipo de instituição, divididos em 3 grupos: "solvência e liquidez", "capital e risco" e "rentabilidade e lucratividade". Segundo Matarazzo (2010), após a avaliação individual de cada índice, é possível também efetuar uma verificação conjunta dos indicadores, analisando as suas relações de modo a gerar um quadro global de desempenho da empresa e de sua administração.

Embora a utilização de indicadores seja amplamente realizada, algumas limitações são encontradas. Conforme Silva (2016), a quantidade de indicadores a serem utilizados na análise de uma empresa é um ponto importante: um grande número de indicadores pode chegar a confundir o usuário, enquanto que uma quantidade muito pequena pode não ser suficiente para tirar conclusões acerca da saúde financeira do negócio. Callado, Callado e Mendes (2015) argumentam que a definição dos indicadores a serem utilizados faz parte de uma sequência lógica de procedimentos para a implementação de um sistema de avaliação de desempenho.

É necessário que seja feita a avaliação dos indicadores conjuntamente e a definição de quais são os que mais influenciam o resultado da empresa, além de se estabelecer pesos para tais indicadores. Bezerra e Corrar (2006) afirmam que essa definição costuma envolver grande grau de subjetividade, mas que por meio da técnica estatística de análise fatorial é possível encontrar mais objetivamente a importância de cada indicador no resultado da empresa.

A análise fatorial tem o intuito de reduzir a complexidade de um grande número de variáveis em um arranjo menor, considerando as correlações entre as variáveis originais (Mendez \& Rondon, 2012). A aplicação dessa técnica a indicadores econômico-financeiros é exemplificada por Bezerra e Corrar (2006), que abordam os indicadores de empresas seguradoras, e por Carvalho e Bialoskorski (2007), que englobam cooperativas agropecuárias. O estudo de Borges, Benedicto e Carvalho (2014) também utiliza abordagem semelhante, porém aplica a análise fatorial para avaliar o desempenho de cooperativas de crédito rural. Nesse sentido, como destacado por Louzada, Oliveira, Silva e Gonçalves (2016), observa-se que a utilização de técnicas estatísticas é importante na construção de um conjunto de indicadores que permitam avaliar o desempenho de uma entidade.

Diante do exposto, este artigo tem como objetivo identificar, por meio da técnica estatística de análise fatorial, os indicadores econômico-financeiros mais relevantes para a avaliação do desempenho das instituições financeiras bancárias.

Assim, a questão que a presente pesquisa pretende responder pode ser resumida da seguinte forma: quais são os indicadores econômico-financeiros mais relevantes para a avaliação do desempenho das instituições financeiras bancárias brasileiras?

Nota-se que, ao se efetuar a análise de indicadores financeiros, há a possibilidade de agrupar esses indicadores em fatores, que permitem compreender o comportamento dos dados originais. Conforme Pereira (1999), ao invés de propor subjetivamente a criação de um indicador, é possível submeter os dados a uma análise fatorial, e os resultados irão apontar objetivamente para tal agregação de medida.

Dessa forma, a pesquisa contribui para aumentar a capacidade de interpretação dos indicadores econômico-financeiros utilizados para avaliação de desempenho das instituições financeiras bancárias, permitindo que critérios menos subjetivos sejam utilizados e que as variáveis mais importantes sejam identificadas e consideradas.

\section{REFERENCIAL TEÓRICO}

Nessa seção, apresenta-se o arcabouço teórico que sustentou a realização do estudo. Inicialmente, são abordadas as instituições financeiras bancárias e as análises de indicadores econômico-financeiros. Na sequência, discute-se a análise de indicadores para instituições financeiras bancárias e a aplicação da análise fatorial em estudos que avaliam indicadores financeiros. 


\subsection{Instituições financeiras bancárias}

As instituições financeiras bancárias são responsáveis pela intermediação financeira e têm como principal função a busca pela satisfação dos vários agentes econômicos. Conforme Assaf (2012), de um lado estão os tomadores de recursos, que buscam incrementar sua riqueza de ativos reais, e do outro lado estão os credores, que desejam manter o patrimônio em ativos que se valorizem de forma estável e com o mínimo de risco. Sendo assim, as funções básicas dessas instituições são a captação e a aplicação de recursos. Ainda, segundo o mesmo autor, os bancos buscam seus resultados por meio da captação de recursos a uma determinada taxa e a sua aplicação a uma taxa maior. A diferença entre tais taxas é denominada spread.

Essas instituições são importantes para a economia. Auxiliam na transformação do risco e na criação de liquidez. Para Cleary e Hebb (2016), quando essas instituições obtêm depósitos à vista os recursos são captados com alta liquidez e baixo risco; porém, ao retornar com esses recursos para o mercado em forma de empréstimos, elas investem em ativos com baixa liquidez e risco elevado. Dessa maneira, conforme os autores, o risco e a liquidez da operação de intermediação financeira são absorvidos pelo negócio bancário (Cleary \& Hebb, 2016).

Segundo Saunders (2000), esse tipo de instituição deve ter uma regulamentação especial, uma vez que qualquer desvio nas suas funções ou nos serviços prestados pode produzir efeitos negativos na economia. Vale notar que outras entidades prestadoras de serviços de utilidade pública também são sujeitas à fiscalização específica, como as companhias de eletricidade, telefone e água. Dessa forma, por terem funções específicas e oferecerem serviços importantes para a sociedade, as instituições bancárias são obrigadas a atuar dentro de diretrizes regulamentadas por órgãos governamentais fiscalizadores.

O Banco Central do Brasil (BCB) é um dos órgãos responsáveis por essa regulamentação. Dentre outras atribuições, cabe ao Banco Central instituir e divulgar as normas específicas de contabilidade e estatística a serem observadas pelo setor bancário. Em 1987, o BCB instituiu o Plano Contábil das Instituições do Sistema Financeiro Nacional - COSIF (Circular BCB n. 1.273, 1987). A criação desse plano teve como objetivo unificar os diversos planos contábeis existentes à época e uniformizar os procedimentos de registro e elaboração de demonstrações financeiras, o que veio a facilitar o acompanhamento, a análise, a avaliação do desempenho e o controle das instituições integrantes do Sistema Financeiro Nacional (Banco Central do Brasil [BCB], 2015). Assim, o COSIF apresenta os critérios e procedimentos contábeis a serem observados pelas instituições financeiras bancárias, bem como a estrutura de contas e modelos de documentos.

Conforme Jayaraman, Srinivasan e Arunachalam (2014), o setor bancário passou por transformações significativas em todo o mundo desde o início dos anos de 1980, devido ao impacto da evolução tecnológica e da globalização. Ainda, segundo os autores, um aspecto importante desse processo é a consolidação das instituições financeiras bancárias por meio de fusões, incorporações ou reestruturações. Nos países de economia emergente, essa transformação foi impulsionada pela restruturação do sistema bancário proposta pelos governos, visando a uma maior regulamentação e competitividade.

Lee, Hsieh e Yang (2014) afirmam que a competitividade do setor bancário tem incentivado as instituições financeiras a desenvolverem novos produtos para atender à demanda do mercado, aumentando a competitividade e ampliando o volume de serviços ofertados. Diante desse cenário, em que estão inseridas as instituições financeiras bancárias, a análise das demonstrações financeiras desperta interesse tanto para os administradores (internos à empresa) como para os diversos segmentos de analistas externos. Segundo Assaf (2012), esse tipo de análise é tido como um dos mais importantes da administração financeira, pois tem como principal objetivo a avaliação do desempenho econômico-financeiro das organizações.

\subsection{Análises de indicadores econômico-financeiros}

A gestão moderna das organizações tem como característica fundamental a criação de modelos gerenciais que possibilitem a análise do desempenho da empresa. Tais modelos são 
indispensáveis no contexto de globalização e competitividade dos mercados atuais (Borges et al., 2014). Castro (2015) argumenta que a avaliação de desempenho possibilita identificar pontos fortes e fracos de uma organização.

Conforme Matarazzo (2010), a análise das demonstrações financeiras visa a estudar o desempenho econômico-financeiro de uma empresa em um determinado período passado, com o intuito de diagnosticar sua posição atual e produzir resultados que sirvam de base para a previsão de tendências futuras.

Para que se faça a análise do desempenho econômico-financeiro, uma metodologia muito utilizada é a criação de índices por meio da análise das demonstrações financeiras. Esses indicadores relacionam duas contas (ou duas combinações de contas) do Balanço Patrimonial e/ou da Demonstração do Resultado (Herrera, Gomez \& Granadillo, 2012). Matarazzo (2010) salienta que essa avaliação da empresa pode ser bastante simplificada quando se trabalha com os principais indicadores, obtidos a partir do acesso às informações contábeis.

Tais informações contábeis podem ser caracterizadas como a fonte principal para a análise de desempenho de uma organização. Efetuando o cálculo dos indicadores, pode-se ainda definir quais deles serão utilizados como ferramenta de gestão. Para que essa análise seja eficiente, não há necessidade de indicadores complexos ou em grande número, mas sim seleção de um número eficiente de indicadores para a empresa que está sendo analisada. Quando se avalia os indicadores financeiros individualmente e ao longo do tempo, é possível também efetuar comparações com as melhores empresas do setor, criando parâmetros para melhorar o sistema de gestão (Miranda, 2008).

A análise das demonstrações contábeis pode ser desenvolvida para finalidades diversas, tais como decisões de crédito, de investimento e de fusões e aquisições, além de análise de concorrência (Silva, 2016). Matarazzo (2010) destaca ainda que o estudo individual dos balanços fornece informações úteis e fundamentais para formular a estratégia organizacional, o que pode ser feito por meio da comparação do balanço com os orçamentos. Isso faz da análise das demonstrações contábeis um instrumento complementar para a tomada de decisões. Após efetuar um diagnóstico individual de cada indicador, pode-se então fazer uma análise em conjunto dos indicadores, com o intuito de identificar as relações entre eles, buscando identificar um quadro global do desempenho da entidade abordada.

\subsection{Análise de indicadores para instituições financeiras bancárias}

A avaliação de desempenho econômico e financeiro das instituições financeiras bancárias que atuam no Brasil pode ser realizada por meio da análise das demonstrações contábeis. A contabilidade bancária possui algumas especificidades, que fazem com que haja diferenças entre as demonstrações apresentadas pelas instituições financeiras e aquelas apresentadas pelas empresas industriais e comerciais ou outras empresas do setor terciário da economia (Naves, 2007).

Devido às características específicas da intermediação financeira, o gerenciamento da liquidez das instituições financeiras não é uma tarefa fácil de ser executada. Assaf (2012) salienta que o negócio de intermediação feito por meio de depósitos (captação de recursos para o banco) representa uma obrigação com terceiros e é registrado pela contabilidade como passivo. A aplicação desses recursos é considerada ativo. Pode estar na forma de caixa ou na forma de empréstimos concedidos, por exemplo. Em outras palavras, as instituições financeiras bancárias "trocam" uma obrigação (depósito à vista) por um direito (empréstimos a receber). Isso gera a dificuldade na equalização dos prazos de recebimento e de pagamento, além de uma grande dificuldade na estrutura dos ativos (Assaf, 2012).

Como forma de facilitar a gestão das instituições financeiras, tem-se utilizado a criação de indicadores econômico-financeiros. Tais indicadores têm a finalidade de avaliar o desempenho da empresa em termos de geração de resultados financeiros (Miranda, 2008). A rentabilidade proporcionada por uma empresa é resultado das decisões que são tomadas em relação a políticas de estruturação de capitais, formas de comercialização e administração dos recursos que estão à disposição dos administradores. Para se fazer uma avaliação econômico- 
financeira de bancos, há a necessidade de tentar eleger alguns indicadores que sejam importantes para a análise de suas demonstrações contábeis.

Porém, conforme Miranda (2008), estudos sobre a análise de demonstrações contábeis de instituições bancárias, por meio de indicadores, ainda são escassos no Brasil. Segundo o autor, observa-se que são raras as publicações nacionais sobre o assunto e se baseiam muito em metodologias específicas, como a CAMELS (Capital, Qualidade dos Ativos, Qualidade da Gestão, Resultados e Liquidez) - que foi desenvolvida por órgãos de supervisão bancária.

Alguns autores sugerem a utilização de diferentes indicadores que representem de forma adequada a realidade das entidades do setor bancário. Nesse contexto, destaca-se a abordagem proposta por Assaf (2012), que sugere 3 blocos principais de indicadores, os quais devem ser utilizados para a análise econômico-financeira de instituições bancárias. $\mathrm{O}$ autor apresenta o cálculo de 17 indicadores, classificados em 3 grupos. Na Tabela 1, apresentam-se as fórmulas de cálculo e os conceitos a eles referentes.

Tabela 1

Fórmulas e conceitos dos indicadores de desempenho econômico-financeiro Indicadores de Solvência e Liquidez

Encaixe Voluntário (EV) = Disponibilidades / Depósitos à Vista

Identifica a capacidade financeira imediata em cobrir saques contra depósitos.

Liquidez Imediata (LI) = (Disponibilidades + Aplicações Interfinanceiras) / Depósitos à Vista

Identifica a capacidade da instituição para cobrir depósitos à vista e parte daqueles a prazo.

Empréstimos sobre Depósitos (ESD) = Operações de Crédito / Depósitos

Revela, para cada $R \$ 1,00$ de capital emprestado, quanto foi captado sobre a forma de depósitos.

Participação dos Empréstimos (PDE) = Operações de Crédito / Ativo Total

Identifica o percentual do ativo total que se encontra aplicado em operações de crédito. Indicadores de Capital e Risco

Independência Financeira (IF) = Patrimônio Líquido / Ativo Total

Identifica o grau de independência financeira com relação à utilização de recursos de terceiros.

Leverage (LEV) = Ativo Total / Patrimônio Líquido

Identifica o grau de alavancagem da instituição na utilização dos ativos.

Relação Capital / Depositantes (RCD) = Patrimônio Líquido / Depósitos

Identifica a relação entre a utilização de recursos próprios e a captação sob a forma de depósitos.

Imobilização do Capital Próprio (ICP) = Ativo Permanente / Patrimônio Líquido

Identifica o grau de imobilização em relação aos recursos próprios.

Índice de Sensibilidade dos Juros (ISJ) = Ativos Sensíveis / Passivos Sensíveis

Identifica a forma como os juros dos ativos e passivos sensíveis se correlacionam com o mercado. Indicadores de Rentabilidade e Lucratividade

Retorno sobre o PL (RPL) = Lucro Líquido / Patrimônio Líquido

Fornece o percentual auferido como consequência das margens de lucro em relação ao capital próprio.

Retorno sobre o Investimento Total (RIT) = Lucro Líquido / Ativo Total

Mostra os resultados das oportunidades de negócio acionadas pela instituição.

Margem Líquida (ML) = Lucro Líquido / Receita de Intermediação Financeira

Permite avaliar a função básica de intermediação financeira da instituição.

Margem Financeira (MF) = Resultado Bruto de Intermediação Financeira / Ativo Total

Permite avaliar o resultado bruto da intermediação financeira antes do risco de crédito.

Lucratividade dos Ativos (LA) = Receitas de Intermediação Financeira / Ativo Total

Permite avaliar os resultados da intermediação financeira provenientes dos investimentos no ativo total.

Custo Médio de Captação (CMC) = Despesas Financeiras de Captação / Depósitos a Prazo

Permite avaliar a relação entre despesas financeiras de captação e depósitos a prazo.

Juros Passivos (JP) = Despesa de Intermediação / Passivo Total

Refere-se às despesas de capital tomado nas diversas modalidades de investimento.

Eficiência (EF) = Despesas Operacionais / Receitas de Intermediação Financeira

Permite avaliar a necessidade de estrutura operacional para a manutenção da operação.

Nota. Fonte: Adaptado de Assaf, A., Neto. (2012). Estrutura e análise de balanços: um enfoque econômico

financeiro (10a ed.). São Paulo, SP. Atlas.

O primeiro grupo é o de Solvência e Liquidez, que busca evidenciar os recursos próprios da organização em relação às suas obrigações, e tenta refletir a competência em atender às demandas por recursos de caixa, de forma a cobrir os passivos financeiros. Já o segundo grupo é o de Capital e Risco, que tem sua estrutura composta de indicadores que avaliam o volume de capital próprio da instituição, ou o mínimo de capital que deve ser 
conservado por ela (embora seja importante ressaltar que esses indicadores não avaliam o risco operacional nem o risco dos ativos).

Por fim, o terceiro grupo é o de Rentabilidade e Lucratividade, que tem sua composição estruturada por indicadores que avaliam a maximização da riqueza da organização por meio da relação risco-retorno (Assaf, 2012). Todos os indicadores mencionados são calculados com base em contas contábeis utilizadas pelas instituições bancárias, inclusive as previstas no COSIF. Com isso, refletem as particularidades das características econômico-financeiras desse setor.

\subsection{Aplicação da análise fatorial em estudos que avaliam indicadores financeiros}

Ao se efetuar a análise de indicadores financeiros, há a possibilidade de agrupá-los em fatores que permitam compreender o comportamento dos dados originais. Pereira (1999) afirma que o pesquisador pode intuir que várias de suas medidas devam compor um fator, mas, ao invés de propor subjetivamente a criação de um indicador, pode preferir submeter seus dados a uma análise fatorial. $E$ os resultados dessa análise irão apontar objetivamente para tal agregação de medidas.

A análise fatorial tem o intuito de reduzir a complexidade de um grande número de variáveis em um arranjo menor, com a finalidade de explicar o fenômeno de maneira mais minuciosa. Esse tipo de técnica multivariada aborda o problema de analisar a estrutura das correlações entre um grande número de variáveis, definindo um conjunto de dimensões latentes comuns chamadas fatores (Mendez \& Rondon, 2012).

Assim, por meio da aplicação de tal técnica, pode-se identificar os principais indicadores que deverão ser considerados para a análise do desempenho econômico-financeiro das organizações. Conforme Castro (2015), essa metodologia é utilizada com o objetivo de sintetizar e validar as relações observadas. Tal objetivo é alcançado a partir da identificação de um número mínimo de fatores que expliquem uma parcela máxima da variância de todos os indicadores.

A utilização da análise fatorial em modelos relacionados ao desempenho econômicofinanceiro pode ser vista em alguns trabalhos científicos como o de Borges et al. (2014). Os autores propuseram um modelo parcimonioso de análise econômico-financeira composto dos principais indicadores provenientes da análise das demonstrações financeiras para os anos de 2010 e 2011, por meio da Análise Fatorial em um grupo de 44 cooperativas de crédito rural do estado de Minas Gerais.

O estudo de Bezerra e Corrar (2006) também propôs uma metodologia que pudesse diminuir o grau de subjetividade na escolha de indicadores para avaliar empresas e que pudesse ser feita de forma simultânea com vários indicadores. A análise fatorial foi utilizada para seleção dos indicadores que analisaram 132 empresas seguradoras da Superintendência de Seguros Privados (SUSEP), no ano de 2001.

Já a pesquisa de Carvalho e Bialoskorski (2007) procurou identificar, por meio da análise fatorial, quais os indicadores contábeis com maior relevância para a avaliação do desempenho de cooperativas agropecuárias pertencentes a determinado programa de Desenvolvimento do Cooperativismo do estado de São Paulo, no ano de 2000. Foram abordados 15 indicadores de desempenho financeiro para as 91 cooperativas analisadas.

Especificamente, em relação às instituições financeiras bancárias, não foram identificados estudos científicos que aplicassem a análise fatorial no intuito de favorecer a mensuração do desempenho econômico-financeiro. Observa-se, então, uma oportunidade de aplicação dessa técnica, que se mostra relevante para a identificação dos principais indicadores e que poderá trazer contribuições significativas para melhorar a análise do desempenho de tais instituições.

\section{PROCEDIMENTOS METODOLÓGICOS}

Essa seção contempla os aspectos metodológicos referentes ao desenvolvimento do estudo, descrevendo a caracterização da pesquisa, a amostra da pesquisa e os procedimentos de análise dos dados e de aplicação da análise fatorial. 


\subsection{Caracterização e amostra da pesquisa}

Este trabalho utiliza uma abordagem quantitativa, segundo a classificação de Martins e Theóphilo (2007). Conforme os autores, nesse tipo de pesquisa os dados são quantificados, e as análises e interpretações utilizam técnicas estatísticas.

O estudo tem caráter descritivo e como principal objetivo a descrição das características de determinada população ou fenômeno e o estabelecimento de relações entre as variáveis (Gil, 2010). Nesse caso, buscou-se observar, analisar, classificar e interpretar as informações referentes ao desempenho econômico e financeiro das instituições financeiras no período abrangido pela pesquisa.

Em relação à coleta de dados para o estudo, foram utilizados dados secundários referentes às demonstrações contábeis das instituições financeiras bancárias com atividades no Brasil. Tais dados foram obtidos por meio do site do Banco Central do Brasil. Foram coletadas as planilhas referentes aos anos de 2011, 2012, 2013 e 2014, com os dados referentes às demonstrações contábeis de tais instituições. As planilhas foram obtidas na seção "50 maiores bancos e o consolidado do Sistema Financeiro Nacional", disponível em link específico no referido site (BCB, 2015).

A amostra da pesquisa foi composta de todas as instituições classificadas, como Banco Comercial, Banco Múltiplo e Caixa Econômica Federal, e que atuaram no Brasil nos anos de 2011 a 2014 (foram selecionadas aquelas que se mantiveram em atividade ao longo dos 4 anos englobados). Dessa forma, a amostra final do estudo engloba 118 instituições financeiras bancárias. Vale mencionar que a amostra contemplou tanto as instituições de origem brasileira quanto as estrangeiras que têm filial no Brasil. A partir dos dados correspondentes a cada uma dessas instituições, foram calculados os indicadores de desempenho econômico-financeiro a elas referentes.

\subsection{Procedimentos de análise dos dados e aplicação da análise fatorial}

As instituições financeiras tiveram seu desempenho medido numericamente por meio da análise de suas demonstrações contábeis. O modelo de demonstrações utilizado segue o padrão COSIF (Circular BCB n. 1.273, 1987). Foram calculados os 17 indicadores de desempenho econômico-financeiro (explicitados na Tabela 1, subseção 2.3), propostos por Assaf (2012).

Ressalta-se que todas as contas contábeis necessárias para os cálculos são diretamente disponibilizadas pelas demonstrações contábeis no padrão COSIF, exceto as referentes ao indicador de sensibilidade dos juros. Para o cálculo desse indicador primeiramente foi feita a classificação dos ativos e passivos sensíveis às variações da taxa de juros. Conforme Assaf (2012), as principais contas patrimoniais classificadas como ativos sensíveis são as de aplicações interfinanceiras, títulos e valores mobiliários, e operações de créditos; e as principais contas patrimoniais classificadas como passivos sensíveis são as de depósitos remunerados, captação em mercado aberto, obrigações por empréstimo e repasses, e aceites e emissões de títulos. O indicador foi calculado considerando essas contas para a composição dos ativos e passivos sensíveis.

Os 17 indicadores foram calculados para cada uma das instituições financeiras nos anos de 2011, 2012, 2013 e 2014. Tais dados foram analisados por meio da metodologia estatística multivariada de análise fatorial. Para identificar os indicadores econômicofinanceiros mais relevantes para a avaliação do desempenho das instituições financeiras bancárias brasileiras, utilizou-se a técnica estatística de análise fatorial. Embora essa utilização para avaliar o desempenho das organizações seja amplamente efetuada, algumas limitações são encontradas. Para Silva (2016), a quantidade de indicadores a serem usados na análise é um fator importante a ser considerado, já que o emprego de muitos indicadores pode confundir o usuário e o de uma quantidade muito pequena pode não ser suficiente para a avaliação financeira de uma empresa.

Segundo Januzzi, Coelho, Gonçalves e Vieira (2015), definir quais variáveis devem ser consideradas para o diagnóstico do desempenho das empresas é um aspecto relevante. É importante que se avalie todos os indicadores conjuntamente e se defina quais os que mais 
influenciam o resultado da empresa, além de se estabelecer pesos para tais indicadores. Bezerra e Corrar (2006) afirmam que essa definição costuma envolver grande grau de subjetividade. Porém, também colocam que é possível encontrar a importância de cada indicador no resultado da empresa, por meio da técnica estatística denominada análise fatorial. Conforme Hair, Black, Babin, Anderson e Tatham (2009), a análise fatorial transforma as variáveis originais em variáveis novas, não correlacionadas, chamadas fatores. Cada fator é uma combinação linear das variáveis originais. Uma medida da quantidade de informação transferida para cada fator é sua variância. Por essa razão, os fatores são arranjados em ordem decrescente em relação à variância. Buesa, Heijs e Baumert (2010) explicitam que a análise fatorial busca definir a estrutura subjacente em uma matriz de dados, e sua principal finalidade é reduzir um conjunto composto de um grande número de variáveis em um pequeno número de fatores que possa ter a capacidade de explicar a sintetização dos dados originais.

Destaca-se também que o modelo desenvolvido, ao aplicar a análise fatorial, deve ser parcimonioso. Significa que precisa explicar o máximo de variância a partir do menor número possível de variáveis, de forma que conduza a resultados consistentes e produza informações relevantes (Puente-Palacios \& Laros, 2009). De acordo com Viana (2005), para que se possa aplicar o método de análise fatorial é necessário que exista relação entre as variáveis, pois com ele será possível identificar grupos de variáveis correlacionadas.

Após verificar a correlação entre as variáveis, o modelo foi inicialmente desenvolvido com os 17 indicadores de desempenho econômico-financeiro anteriormente apresentados (Tabela 1). Posteriormente, buscando um melhor poder de explicação dos fatores, foram excluídas as variáveis que tinham baixo poder de relacionamento com as demais e foram repetidos os procedimentos referentes à análise fatorial.

A adequação da análise também foi provada por meio do teste de Kaiser-Meyer-Olkim (KMO) e do teste de esfericidade de Bartlett. O número de fatores foi selecionado por meio do método da raiz latente (baseado na medida de variância que o fator explica), definindo-se a quantidade de fatores com autovalor maior que 1 (Hair et al., 2009).

O método de extração foi a análise de componentes principais. O objetivo desse método é produzir um primeiro fator que tenha a máxima variância explicada. Depois, com a definição do primeiro fator e sua carga associada, a análise irá buscar um segundo fator que maximize a variância que ele explica. Tem-se a continuação do procedimento até que haja tantos fatores gerados quanto existam variáveis ou até que o analista conclua que o número de fatores utilizáveis foi exaurido (Hair et al., 2009).

A adequação de cada uma das variáveis também foi analisada individualmente. Para isso, utilizou-se o teste de Measure of Sampling Adequacy (MSA), obtido por meio da matriz de anti-imagem, e a análise da tabela de comunalidades.

As cargas fatoriais foram calculadas e apresentadas. Posteriormente foi determinado o ajuste do modelo e sua interpretação. Analisou-se a variância explicada pelos fatores retidos por meio da Matriz de Variância Total Explicada. Para facilitar a identificação dos indicadores que compunham cada um dos fatores, foi utilizada a matriz após a rotação dos fatores. $O$ método aplicado foi o Varimax, de rotação ortogonal. Hair et al. (2009) afirmam que a rotação ortogonal tem como objetivo a simplificação das linhas e colunas da matriz fatorial, facilitando a interpretação dos resultados. A partir da maximização da soma de variâncias de cargas exigidas da matriz fatorial, tenta-se carregar os pesos para que cada indicador esteja relacionado a um dos fatores gerados.

O software utilizado para a análise dos dados foi o programa computacional Statistical Package for Social Science (SPSS ${ }^{\circledR}$ ), versão 17.0.

\section{RESULTADOS E DISCUSSÕES}

Para verificar a adequação do emprego da análise fatorial, inicialmente verificou-se a matriz de correlações entre as variáveis abordadas. Observou-se um número significativo de variáveis com coeficiente de correlação de Pearson acima de $30 \%$ e estatisticamente significativos (ao nível de significância de 1\%). Isso indica a viabilidade da utilização da análise fatorial. Assim, é possível dar prosseguimento à aplicação dessa técnica. 


\subsection{Análise com todos os indicadores}

A princípio, buscou-se estabelecer os fatores utilizando todos indicadores ao mesmo tempo, procurando agregar todos os indicadores em fatores com alta comunalidade e perda mínima de informação. Porém, como a análise fatorial busca a criação de fatores que expliquem simultaneamente todos os indicadores, o fato de existirem indicadores que possuam um pequeno ou nenhum relacionamento com os demais faz com que aquela análise atinja resultados pouco satisfatórios. Observou-se que isso ocorreu, nessa tentativa de unir todos os indicadores em uma única análise de dados.

O Teste de Esfericidade de Bartlett rejeitou a hipótese nula de que a matriz de correlação dos dados é a matriz identidade, ao valor de $p<0,001$ (altamente significativo). Já o Teste de Kaiser-Meyer-Olkim, que mede a adequacidade amostral, apresentou valor de aproximadamente 0,562. Hair et al. (2009) recomendam um mínimo de 0,500 para que a análise se mostre apropriada. Assim, esses testes indicaram a adequação da análise fatorial exploratória para a análise e o tratamento dos dados.

Aplicou-se, então, a análise fatorial para os dezessete indicadores. Inicialmente, foram retidos sete fatores. A Matriz de Variância Total Explicada permite verificar o grau de explicação atingido por tais fatores. Conforme apresentado na Tabela 2, com a extração dos sete fatores, o poder de explicação é de $76,33 \%$ das variações totais dos dezessete indicadores inicialmente utilizados.

Tabela 2

Matriz de Variância Total Explicada para a análise com 17 indicadores

\begin{tabular}{|c|c|c|c|c|c|c|c|c|c|}
\hline \multirow{2}{*}{$\begin{array}{l}\text { Compo- } \\
\text { nentes }\end{array}$} & \multicolumn{3}{|c|}{ Valores próprios iniciais } & \multicolumn{3}{|c|}{$\begin{array}{l}\text { Soma de quadrados de } \\
\text { cargas extraídas }\end{array}$} & \multicolumn{3}{|c|}{$\begin{array}{c}\text { Soma de quadrados de cargas } \\
\text { rotacionadas }\end{array}$} \\
\hline & Total & $\begin{array}{c}\% \text { de } \\
\text { Variância }\end{array}$ & $\begin{array}{l}\% \text { Cumu- } \\
\text { lativo }\end{array}$ & Total & $\begin{array}{c}\text { \% de } \\
\text { Variância }\end{array}$ & $\begin{array}{l}\% \text { Cumu- } \\
\text { lativo }\end{array}$ & Total & $\begin{array}{c}\% \text { de } \\
\text { Variância }\end{array}$ & $\begin{array}{l}\% \text { Cumu- } \\
\text { lativo }\end{array}$ \\
\hline 1 & 3,104 & 18,257 & 18,257 & 3,104 & 18,257 & 18,257 & 2,971 & 17,476 & 17,476 \\
\hline 2 & 2,564 & 15,082 & 33,339 & 2,564 & 15,082 & 33,339 & 2,259 & 13,288 & 30,764 \\
\hline 3 & 2,316 & 13,625 & 46,964 & 2,316 & 13,625 & 46,964 & 2,071 & 12,185 & 42,949 \\
\hline 4 & 1,486 & 8,743 & 55,707 & 1,486 & 8,743 & 55,707 & 1,673 & 9,842 & 52,790 \\
\hline 5 & 1,325 & 7,792 & 63,499 & 1,325 & 7,792 & 63,499 & 1,467 & 8,630 & 61,421 \\
\hline 6 & 1,155 & 6,793 & 70,292 & 1,155 & 6,793 & 70,292 & 1,310 & 7,709 & 69,129 \\
\hline 7 & 1,026 & 6,038 & 76,330 & 1,026 & 6,038 & 76,330 & 1,224 & 7,201 & 76,330 \\
\hline 8 & 0,871 & 5,121 & 81,451 & & & & & & \\
\hline 9 & 0,805 & 4,735 & 86,186 & & & & & & \\
\hline 10 & 0,622 & 3,660 & 89,846 & & & & & & \\
\hline 11 & 0,490 & 2,883 & 92,729 & & & & & & \\
\hline 12 & 0,440 & 2,586 & 95,314 & & & & & & \\
\hline 13 & 0,324 & 1,907 & 97,222 & & & & & & \\
\hline 14 & 0,288 & 1,694 & 98,916 & & & & & & \\
\hline 15 & 0,152 & 0,896 & 99,812 & & & & & & \\
\hline 16 & 0,032 & 0,187 & 99,999 & & & & & & \\
\hline 17 & 0,000 & 0,001 & 100,000 & & & & & & \\
\hline
\end{tabular}

Nota. Fonte: dados da pesquisa.

Apesar de os testes indicarem a possibilidade de aplicação da análise fatorial com todas as variáveis (os dezessete indicadores), optou-se por aumentar o poder de explicação dos fatores analisando cada variável e, se necessário, retirando algumas variáveis da análise. A escolha dos indicadores que seriam excluídos da análise foi feita com base em dois critérios: a análise da matriz de anti-imagem e a análise da tabela de comunalidades.

Em relação ao primeiro critério, a matriz de anti-imagem indica o poder de explicação dos fatores em cada uma das variáveis analisadas. Hair et al. (2009) afirmam que o teste KMO avalia o quão apropriada é a aplicação da análise fatorial de forma geral, e que também se 
pode avaliar as variáveis individuais, as quais devem ser analisadas por meio do indicador MSA - Measure of Sampling Adequacy.

A diagonal da parte inferior da matriz de anti-imagem indica o MSA para cada uma das variáveis do modelo. Os valores inferiores a 0,500 são considerados muito pequenos para análise, e nesses casos indicam variáveis que podem ser excluídas. Seguindo esse critério, foram retirados da análise os indicadores: Juros Passivos (JP), Custo Médio de Captação (CMC), Margem Financeira (MF) e Lucratividade dos Ativos (LA), que apresentaram um nível de MSA menor do que 0,500 nas análises realizadas.

Já em relação ao segundo critério, analisou-se a comunalidade de cada um dos indicadores, com o intuito de avaliar a proporção da variância comum dentro de cada variável. Segundo Hair et al. (2009), os valores estimados das comunalidades, após a extração dos fatores, variam entre 0,0 e 1,0, de forma que se o valor for 0,0 não há a variância parcial e se o valor for 1,0 há $100 \%$ de variância comum. Field (2009) afirma que indicadores com valores de comunalidade inferiores a 0,700 devem ser descartados. Seguindo esse critério, foram retirados da análise os indicadores: Participação dos Empréstimos (PDE), Eficiência (EF), Imobilização do Capital Próprio (ICP), Leverage (LEV) e Independência Financeira (IF), os quais obtiveram valores inferiores a 0,700 nas análises realizadas.

\subsection{Análise final com oito indicadores}

Após extrair os indicadores apontados pelos critérios da matriz anti-imagem (MSA) e da tabela de comunalidades, percebeu-se uma grande melhora no poder de explicação. O modelo final engloba os seguintes indicadores: Encaixe Voluntário (EV), Liquidez Imediata (LI), Índice Empréstimos/Depósitos (ESD), Relação Capital/Depositantes (RCD), Índice de Sensibilidade de Juros (ISJ), Retorno sobre o Patrimônio Líquido (RPL), Retorno sobre o Investimento Total (RIT) e Margem Líquida (ML).

$\mathrm{O}$ teste de KMO ficou em 0,588 (maior do que 0,500) e o teste de esfericidade continuou inferior a 0,001, o que valida a utilização da análise fatorial. A Matriz de Correlação anti-imagem apresentou todos os valores das variáveis de MSA individuais superiores a 0,500 , evidenciando a adequacidade amostral. Além disso, todos os indicadores da matriz de comunalidades apresentaram valor superior a 0,700 (conforme pode ser verificado na Tabela 3), o que indica alta proporção de variância comum dentro das variáveis.

Tabela 3

Tabela de comunalidades para a análise final com 8 indicadores

\begin{tabular}{ccc}
\hline Variável & Inicial & Extração \\
\hline EV & 1,000 & 0,986 \\
\hline LI & 1,000 & 0,706 \\
\hline ESD & 1,000 & 0,899 \\
\hline RCD & 1,000 & 0,946 \\
\hline ISJ & 1,000 & 0,982 \\
\hline RPL & 1,000 & 0,768 \\
\hline RSIT & 1,000 & 0,959 \\
\hline ML & 1,000 & 0,893
\end{tabular}

Nota. Fonte: dados da pesquisa.

Com a aplicação da análise fatorial para esses oito indicadores, foram retidos três fatores. O método de extração utilizado foi a análise dos componentes principais. A Variância Total Explicada mostrou um nível de explicação significativamente superior ao obtido nas tentativas anteriores. O percentual de variação explicada pelos três fatores foi de aproximadamente $89,23 \%$, conforme pode ser visualizado na Tabela 4. 
Tabela 4

Matriz de Variância Total Explicada para a Análise Final com 8 Indicadores

\begin{tabular}{|c|c|c|c|c|c|c|c|c|c|}
\hline \multirow{2}{*}{$\begin{array}{l}\text { Compo- } \\
\text { nentes }\end{array}$} & \multicolumn{3}{|c|}{ Valores próprios iniciais } & \multicolumn{3}{|c|}{$\begin{array}{c}\text { Soma de quadrados de cargas } \\
\text { extraídas }\end{array}$} & \multicolumn{3}{|c|}{$\begin{array}{c}\text { Soma de quadrados de cargas } \\
\text { rotacionadas }\end{array}$} \\
\hline & Total & $\begin{array}{c}\% \text { de } \\
\text { Variância }\end{array}$ & $\begin{array}{l}\% \text { Cumu- } \\
\text { lativo }\end{array}$ & Total & $\begin{array}{c}\% \text { de } \\
\text { Variância }\end{array}$ & $\begin{array}{l}\% \text { Cumu- } \\
\text { lativo }\end{array}$ & Total & $\begin{array}{c}\% \text { de } \\
\text { Variância }\end{array}$ & $\begin{array}{c}\% \text { Cumu- } \\
\text { lativo }\end{array}$ \\
\hline 1 & 2,806 & 35,070 & 35,070 & 2,806 & 35,070 & 35,070 & 2,581 & 32,259 & 32,259 \\
\hline 2 & 2,541 & 31,766 & 66,837 & 2,541 & 31,766 & 66,837 & 2,552 & 31,897 & 64,156 \\
\hline 3 & 1,791 & 22,391 & 89,227 & 1,791 & 22,391 & 89,227 & 2,006 & 25,072 & 89,227 \\
\hline 4 & 0,414 & 5,177 & 94,404 & & & & & & \\
\hline 5 & 0,352 & 4,406 & 98,810 & & & & & & \\
\hline 6 & 0,037 & 0,465 & 99,276 & & & & & & \\
\hline 7 & 0,033 & 0,408 & 99,684 & & & & & & \\
\hline 8 & 0,025 & 0,316 & 100,000 & & & & & & \\
\hline
\end{tabular}

Nota. Fonte: dados da pesquisa.

Ainda pela observação da Tabela 4, nota-se que o número dos "Valores próprios iniciais" se iguala ao número de variáveis em análise, que nesse caso é de oito. Entretanto, desses componentes apenas três possuem valor total maior do que 1,0 e por isso o número de fatores retidos é de somente três. O componente 1 apresentou valor de 2,806, o componente 2 o valor de 2,541, e o componente 3 apresentou o valor de 1,791.

Esses fatores representam três dimensões subjacentes aos dados, úteis na análise de desempenho das instituições financeiras bancárias que são objeto deste estudo. Com isso, ao invés de se trabalhar com os oito indicadores financeiros de desempenho, pode-se utilizar apenas três fatores, uma vez que são responsáveis por explicar $89,227 \%$ da associação total entre os dados. A utilização desses fatores está em consonância com a abordagem de Castro (2015), que enfatiza que a análise fatorial é utilizada para sintetizar e validar as relações observadas entre os indicadores financeiros. Assim, identifica-se um número mínimo de fatores que explicam uma parcela máxima da variância dos indicadores.

\subsection{Consideração sobre os indicadores excluídos da análise}

Uma série de testes foi feita para verificar se era possível criar agrupamentos entre os indicadores excluídos da análise. Nesse sentido, verificou-se se esses indicadores poderiam resultar em outros fatores que, isolados dos três inicialmente identificados, comporiam o modelo de avaliação das instituições financeiras bancárias. Porém, os testes revelaram a impossibilidade de criação de um fator para o agrupamento dos indicadores excluídos no estudo. Em nenhum dos testes realizados houve ajuste satisfatório do modelo, o KMO era menor que 0,500 e/ou as variáveis apresentavam baixa MSA (inferior a 0,500) ou baixa comunalidade (inferior a 0,700).

Logo, observou-se a inadequação de se utilizar um outro fator para essas variáveis, e a escolha dos indicadores que devem fazer parte da avaliação foi feita de forma objetiva, utilizando os critérios da análise fatorial. Corroborou-se, então, o resultado obtido, que conduz à utilização de oito indicadores econômico-financeiros para a análise de desempenho das 118 instituições financeiras bancárias abordadas no estudo.

\subsection{Discussões sobre os fatores obtidos}

A fim de identificar os indicadores financeiros mais significativos para a avaliação de instituições financeiras bancárias e estabelecer a composição dos três fatores gerados pela análise fatorial, observa-se a matriz de componentes rotacionados. Tal matriz foi gerada pelo método Varimax e é apresentada na Tabela 5. 
Tabela 5

Matriz de componentes rotacionados

\begin{tabular}{c|ccc}
\hline & \multicolumn{2}{c}{ Componentes } \\
\hline Variável & $\mathbf{1}$ & $\mathbf{2}$ & $\mathbf{3}$ \\
RIT & 0,971 & \\
ML & 0,926 & \\
RPL & 0,874 & 0,972 & \\
RCD & & 0,948 & 0,989 \\
ESD & & 0,840 & 0,987 \\
LI & & & \\
EV & & & \\
ISJ & & &
\end{tabular}

Nota. Fonte: dados da pesquisa.

Dessa forma, identifica-se quais indicadores fazem parte de cada um dos fatores extraídos. Segundo Matarazzo (2010), é importante efetuar uma análise em conjunto dos indicadores e identificar as relações entre eles, buscando analisar um quadro global do desempenho da entidade. De acordo com os resultados obtidos (Tabela 5), as instituições financeiras bancárias podem ter seu desempenho avaliado por meio de três fatores.

O primeiro fator é denominado Rentabilidade e Lucratividade e é responsável por $35,07 \%$ das variâncias (vide Tabela 4). Esse fator é composto dos indicadores Retorno sobre o Investimento Total (RIT), Margem Líquida (ML) e Retorno sobre o Patrimônio Líquido (RPL), e permite avaliar a lucratividade auferida pela instituição financeira bancária, principalmente pela função básica de intermediação financeira.

O segundo fator é denominado Capital e Liquidez. É responsável por $31,77 \%$ das variâncias. Ele é composto dos indicadores Relação Capital/Depositantes (RCD), Índice Empréstimos/Depósitos (ESD) e Liquidez Imediata (LI). Permite avaliar a composição de capital em relação aos depósitos e a capacidade de cobrir os depósitos com recursos correntes.

E o terceiro fator é denominado Encaixe e Sensibilidade aos Juros, responsável por $22,39 \%$ das variâncias. É composto dos indicadores Encaixe Voluntário (EV) e Índice de Sensibilidade de Juros (ISJ), permitindo avaliar a capacidade financeira imediata e a sensibilidade às variações nas taxas de juros do mercado.

Os indicadores podem ser agrupados em três fatores, que representam as principais dimensões que devem ser consideradas ao se analisar a situação econômico-financeira dessas entidades. $\mathrm{E}$ tais fatores podem ser transformados em novos indicadores (Rentabilidade e Lucratividade; Capital e Liquidez; e Encaixe e Sensibilidade aos Juros), permitindo o ranqueamento e comparação das instituições com base nas cargas dos fatores. Para calcular os valores desses novos indicadores referentes a uma das instituições, basta multiplicar os scores apresentados na matriz "Component Score Coefficient" (apresentada na Tabela 6) pelos indicadores iniciais e somá-los, em cada um dos casos.

Tabela 6

Matriz "Component Score Coefficient"

\begin{tabular}{l|ccc}
\hline \multirow{2}{*}{ Variável } & \multicolumn{3}{c}{ Componentes } \\
\cline { 2 - 4 } & $\mathbf{1}$ & $\mathbf{2}$ & $\mathbf{3}$ \\
\hline RIT & 0,379 & 0,002 & 0,018 \\
ML & 0,355 & $-0,004$ & $-0,022$ \\
RPL & 0,356 & $-0,015$ & 0,104 \\
RCD & $-0,009$ & 0,381 & 0,000 \\
ESD & $-0,004$ & 0,372 & $-0,002$ \\
LI & $-0,006$ & 0,329 & $-0,005$ \\
EV & 0,044 & 0,000 & 0,502 \\
ISJ & 0,045 & $-0,006$ & 0,501
\end{tabular}

Nota. Fonte: dados da pesquisa. 
Dessa forma, os indicadores RIT, ML, RPL, RCD, ESD, LI, EV e ISJ devem compor o modelo a ser considerado para a análise de desempenho das instituições englobadas pelo estudo. Esses resultados se aproximam dos obtidos por Borges et al. (2014) para as cooperativas de crédito. Os autores identificaram dez indicadores econômico-financeiros mais relevantes para a avaliação do desempenho dessas cooperativas, e é possível observar que seis deles são comuns aos identificados para as instituições financeiras bancárias na presente pesquisa (RIT, ML, RPL, RCD, ESD e LI).

Vale destacar que, por meio dos resultados obtidos pela modelagem, pode-se avaliar o desempenho das instituições financeiras bancárias em relação a cada um dos três fatores, formando rankings e comparando as diferentes instituições, bem como a sua evolução ao longo dos anos. Portanto, contribui-se para identificar os pontos fortes e fracos da instituição, além de diagnosticar sua posição atual e de produzir resultados que sirvam de base para a previsão de tendências futuras, conforme preconizado por Matarazzo (2010) e Castro (2015).

Esses fatores refletem as características do negócio bancário, conforme explicitado por Assaf (2012). Segundo tal autor, as instituições financeiras, para atuar em ambientes de concorrência, desenvolvem suas estratégias de mercado visando a maximizar seus resultados operacionais. Nesse sentido, os serviços financeiros oferecidos pelos bancos são gerenciados de maneira a minimizar seus custos e expandir o volume de suas aplicações e, consequentemente, de suas receitas. Essas estratégias refletem principalmente nos fatores "Rentabilidade e Lucratividade" e "Capital e Liquidez", os mais importantes para analisar o desempenho das instituições financeiras (juntos, os dois fatores representam $66,84 \%$ da variância dos dados, como apresentado na Tabela 4).

\section{CONCLUSÃO}

A partir da utilização da análise fatorial, foi possível identificar os indicadores que explicam o máximo de variância a partir do menor número possível de variáveis. Conclui-se que os indicadores econômico-financeiros mais relevantes para a avaliação do desempenho das instituições financeiras bancárias brasileiras são: Retorno sobre o Investimento Total (RIT), Margem Líquida (ML), Retorno sobre o Patrimônio Líquido (RPL), Relação Capital/Depositantes (RCD), Índice Empréstimos/Depósitos (ESD), Liquidez Imediata (LI), Encaixe Voluntário (EV) e Índice de Sensibilidade de Juros (ISJ). Assim, nota-se a necessidade de acompanhamento de um número de indicadores bem menor do que o apresentado originalmente.

Esses oito indicadores podem, ainda, ser substituídos por três fatores, os quais explicam aproximadamente $89,23 \%$ da variância total dos dados. Os fatores "Rentabilidade e Lucratividade", "Capital e Liquidez" e "Encaixe e Sensibilidade aos Juros" permitem classificar e comparar o desempenho das instituições, revelando os principais aspectos que devem ser considerados ao analisá-las.

Dessa maneira, com a utilização desses indicadores e a aplicação da Análise Fatorial, foi possível resumir os dados de forma a poderem auxiliar na avaliação econômico-financeira das instituições atuantes no setor bancário. Por meio dos resultados obtidos, tomadores de decisões financeiras poderão se concentrar prioritariamente nos indicadores e fatores mais significativos para o desempenho dessas instituições, o que favorece a otimização da eficiência da gestão econômico-financeira.

Em relação ao meio acadêmico, o estudo fornece uma contribuição metodológica para se avaliar o desempenho das instituições do setor bancário e aumentar o nível de conhecimento sobre os indicadores econômico-financeiros dessas instituições. A originalidade da pesquisa está na aplicação da análise fatorial. Os novos indicadores resultantes dessa aplicação podem ser utilizados em outros estudos, de forma a complementar as análises com os indicadores tradicionais.

Além disso, a pesquisa contribui para que os gestores, analistas e investidores notem que é possível consolidar indicadores financeiros que avaliem o desempenho das empresas de um setor específico. Auxilia, então, para que tais agentes estabeleçam um menor número de 
indicadores e simplifiquem o processo de análise das empresas, permitindo um melhor entendimento sobre os dados.

Como limitação do estudo, vale ressaltar que a análise foi efetuada a partir dos dezessete indicadores pré-definidos. Dessa forma, outros indicadores econômico-financeiros não foram abordados. Para futuras pesquisas, sugere-se que diferentes indicadores sejam utilizados com a aplicação da análise fatorial, e que sejam feitas comparações com os resultados aqui apresentados. Além disso, recomenda-se que os indicadores identificados neste estudo sejam utilizados para verificar e comparar o desempenho de diferentes instituições financeiras bancárias ao longo do tempo.

\section{REFERÊNCIAS}

Assaf, A., Neto. (2012). Estrutura e análise de balanços: um enfoque econômico-financeiro (10a ed.). São Paulo, SP. Atlas.

Banco Central do Brasil. (2015). 50 maiores bancos e o consolidado do Sistema Financeiro Nacional. Recuperado de http://www4.bcb.gov.br/top50/port/top50.asp

Bezerra, F. A., \& Corrar, L. J. (2006). Utilização da análise fatorial na identificação dos principais indicadores para avaliação do desempenho financeiro: uma aplicação nas empresas de seguros. Revista Contabilidade \& Finanças, 17(42), 50-62.

Borges, R. C., Benedicto, G. C. de, \& Carvalho, F. de M. (2014). Utilização da análise fatorial para identificação dos principais indicadores de avaliação de desempenho econômicofinanceiro em cooperativas de crédito rural de Minas Gerais. Organizações Rurais \& Agroindustriais, 16(4), 466-480.

Brigham E. F., \& Ehrhardt M. C. (2016). Administração Financeira: teoria e prática (14a ed.). São Paulo, SP: Cengage Learning.

Buesa, M., Heijs, J., \& Baumert, T. (2010). The determinants of regional innovation in Europe: A combined factorial and regression knowledge production function approach. Research Policy, 39(6), 722-735.

Callado, A. A. C., Callado, A. L. C., \& Mendes, E. (2015). Padrões de uso de indicadores de desempenho: uma abordagem multivariada para empresas agroindustriais do setor avícola localizadas no estado de Pernambuco. Latin American Journal of Business Management, 6(2), 216-236.

Carvalho, F. L.; Bialoskorski, S., Neto. (2007). Um ensaio sobre a análise de desempenho em cooperativas agropecuárias. Anais do Congresso USP de Controladoria e Contabilidade, São Paulo, SP, Brasil, 7.

Castro, J. K. (2015). Avaliação de desempenho financeiro de empresas brasileiras de energia a partir da análise fatorial e árvore de decisão. Dissertação de mestrado, Universidade Federal de Santa Catarina - UFSC, Florianópolis, SC, Brasil.

Circular BCB n. 1.273, de 29 de dezembro de 1987 (1987). Às Instituições Financeiras e demais Entidades Autorizadas a Funcionar pelo Banco Central do Brasil. Circular Normativa. Brasília, DF: Banco Central do Brasil.

Cleary, S., \& Hebb, G. (2016). An efficient and functional model for predicting bank distress: in and out of sample evidence. Journal of Banking \& Finance,64, 101-111.

Gil, A. C. (2010). Como elaborar projetos de pesquisa (5a ed.). São Paulo, SP: Atlas.

Hair, J. F., Jr., Black, W. C., Babin, B. J., Anderson, R. E., \& Tatham, R. L. (2009). Análise multivariada de dados (6a ed.). Porto Alegre, RS: Bookman.

Herrera, T. F., Gómez, J. M., \& Granadillo, E. de La H. (2012). Aplicación de análisis discriminante para evaluar el comportamiento de los indicadores financieros en las empresas del sector carbón en Colombia. Entramado, 8(2), 64-73. 
Januzzi, F. V., Coelho, M. de F., Gonçalves, C. A., \& Vieira, L. M. (2015). Robustez na análise de dados financeiros: análise fatorial associada à regressão em painel. Revista Ciências Administrativas, 21(1), 163-183.

Jayaraman, A. R., Srinivasan, M. R., \& Arunachalam, R. (2014). Impact of merger and acquisition on the efficiency of Indian banks: a pre-post analysis using data envelopment analysis. International Journal of Financial Services Management, 7(1), 1-18.

Lee, C. C., Hsieh, M. F., \& Yang, S. J. (2014). The relationship between revenue diversification and bank performance: do financial structures and financial reforms matter? Japan and the World Economy, 29, 18-35.

Louzada, L. C., Oliveira, J. P. D., Silva, A. F. P. da, \& Gonçalves, M. A. (2016). Análise comparativa entre os indicadores econômico-financeiros aplicados às indústrias manufatureiras listadas na Bovespa. REAVI-Revista Eletrônica do Alto Vale do Itajaí, 5(7), 17-36.

Martins, G. A., \& Theóphilo, C. (2007) Metodologia da investigação científica para ciências sociais aplicadas. São Paulo, SP: Atlas.

Matarazzo, D. C. (2010). Análise financeira de balanços: abordagem gerencial (7a ed.). São Paulo, SP: Atlas.

Martínez, C. M., \& Sepúlveda, M. A. R. (2012). Introducción al análisis factorial exploratorio. Revista Colombiana de Psiquiatría, 41(1), 197-207.

Miranda, V. L. (2008). Impacto da adoção das IFRS (Internacional Financial Reporting Standards) em indicadores econômico-financeiros de bancos de alguns países da União Europeia (Dissertação de mestrado). Universidade de São Paulo - USP, São Paulo, SP, Brasil.

Naves, C. D. F. B. (2007). A sustentabilidade financeira das cooperativas de crédito rural: um estudo de caso no estado de São Paulo. Dissertação de mestrado, Universidade de São Paulo - USP, Ribeirão Preto, SP, Brasil.

Pereira, J. C. R. (1999). Análise de dados qualitativos: estratégias metodológicas para as ciências da saúde humanas e sociais. São Paulo, SP: Edusp.

Puente-Palacios, K. E., \& Laros, J. A. (2009). Análise multinível: contribuições para estudos sobre efeito do contexto social no comportamento individual. Estudos de Psicologia, 26(3), 349-61.

Saunders, A. (2000). Administração de instituições financeiras (2a ed.). São Paulo, SP: Atlas.

Silva, J. P. da. (2016). Análise financeira das empresas (13a ed.). São Paulo, SP: Cengage Learning.

Viana, A. B. N. (2005). Estatística Aplicada à Administração: análise do uso em pesquisas na área e construção de ambiente virtual de ensino-aprendizagem. Tese de doutorado, Universidade de São Paulo - USP, Ribeirão Preto, SP, Brasil.

Zha, Y., Liang, N., Wu, M., \& Bian, Y. (2016). Efficiency evaluation of banks in China: A dynamic two-stage slacks-based measure approach. Omega, 60, 60-72. 